\title{
Joining Properties of $\mathrm{CoSb}_{3} / \mathrm{Al} / \mathrm{Ti} / \mathrm{CuMo}$ by Spark Plasma Sintering Process
}

\author{
Min Suk Kim****, Jong Pil Ahn*, Kyoung Hun Kim**, Kyung Ja Kim*, Joo Seok Park*, \\ Won Seon Seo*, and Hyung Sun Kim** \\ *Business Cooperation Center, Korea Institute of Ceramic Engineering and Technology, Seoul 153-801, Korea \\ **School of Materials Engineering, Inha University, Incheon 402-751, Korea \\ (Received October 6, 2014; Revised November 20, 2014; Accepted November 21, 2014)
}

\section{방전플라즈마 소결 공정을 이용한 $\mathrm{CoSb}_{3} / \mathrm{Al} / \mathrm{Ti} / \mathrm{CuMo}$ 접합 특성 \\ 김민숙**** 안종필* · 김경훈*, · 김경자* · 박주석* · 서원선* · 김형순** \\ *한국세라믹기술원 기업협력센터 \\ **인하대학교 신소재공학과}

(2014년 10월 6일 접수 ; 2014년 11월 20일 수정 ; 2014년 11월 21일 채택)

\begin{abstract}
$\mathrm{CoSb}_{3}$-based skutterudite compounds are candidate materials for thermoelectric power generation in the mid-temperature range $(600-900 \mathrm{~K})$ because their thermoelectric properties can be enhanced by doping and filling. The joining property of thermoelectric module electrodes containing thermoelectric materials is of great importance because it can dominate the efficiency of the thermoelectric module. This study examined the properties of $\mathrm{CoSb}_{3} / \mathrm{Al} / \mathrm{Ti} / \mathrm{CuMo}$ joined by the spark plasma sintering technique. Titanium thin foil was used to prevent the diffusion of copper into $\mathrm{CoSb}_{3}$ and Aluminum thin foil was used to improve the adhesion between $\mathrm{CoSb}_{3}$ and Ti. The insertion of an Aluminum interlayer between the Ti and $\mathrm{CoSb}_{3}$ was effective for joining $\mathrm{CoSb}_{3}$ to $\mathrm{Ti}_{\mathrm{b}}$ by forming an intermediate layer at the $\mathrm{Al}-\mathrm{CoSb}_{3}$ boundary without any micro cracks. Specifically, the adhesion strength of the Ti/Al/ $\mathrm{CoSb}_{3}$ joining interface showed a remarkable improvement compared with our previous results, without deterioration of electrical property in the interface.
\end{abstract}

Key words : $\operatorname{CoSb}_{3}$, Thermoelectric, Spark plasma sintering

\section{1. 서 론}

열전 재료는 저온에서 고온에 이르기까지 다양한 온도 조건에서 사용될 수 있고 소음이 없고 환경 오염물질의 배출이 없으며 정밀한 온도 제어가 가능하고 응답속도가 빠르기 때문에 열전냉각 분야, 폐열 등을 이용한 열전 발 전 등 차세대 에너지 소재로 주목 받고 있다. 최근에 이 르러 이러한 열전 재료의 실용화를 위해 소재의 열전변 환 효율과 더불어 열전 소자의 설계가 매우 중요한 부분 으로 인식되고 있는데, 열전변환 효율은 열전변환 소재와 전극 소재에 의해 크게 영향을 받으며 장치의 신뢰성은 장치의 설계에 의하여 크게 영향을 받기 때문에 우수한 특성을 갖는 열전소자를 제조하기 위해서는 열전 소재의 선정과 장치의 설계가 매우 중요하다 할 수 있다. ${ }^{1,2)}$

중고온 온도 영역(약 $600 \sim 900 \mathrm{~K})$ 의 경우에는 자동차의

${ }^{\dagger}$ Corresponding author: Hyung Sun Kim

E-mail : khkim@kicet.ac.kr

Tel : +82-2-3282-7870 Fax : +82-2-3282-2490
배기 폐열 회수 등 실용적인 측면에서 매우 관심이 높은 분야로 지금까지는 주로 이 온도 영역에서 우수한 특성 을 나타내는 $\mathrm{Pb}-\mathrm{Te}$ 계 열전 소재에 대한 연구가 이루어져 왔지만 $\mathrm{Pb}$ 사용에 따른 환경적인 문제로 인하여 향후 사 용상의 제약이 따를 것으로 예상된다., ${ }^{3,4)}$ 이러한 문제를 해결하기 위하여 최근에 Skutterudite 구조를 갖는 $\mathrm{CoSb}_{3}$ 가 매우 주목을 받고 있는데 이는 $\mathrm{CoSb}_{3}$ 가 중고온 영역 에서 안정적이면서도 매우 우수한 열전 성능을 나타내고 있으며 도핑 원소에 따라 $\mathrm{n}$ 형과 $\mathrm{p}$ 형의 열전반도체 제조 가 동시에 가능하기 때문이다. ${ }^{5-8)}$

실용적으로 적용이 가능한 열전 발전 소자를 개발하기 위해서는 우수한 특성을 지닌 열전 소재의 개발뿐만 아 니라 열전 소재를 이용하여 열전 발전 소자를 제조하는 공정의 개발과 더불어 소자를 구성하는 각 소재의 구성 과 이종 소재간의 접합 기술을 확보하는 것이 매우 중요 하다. ${ }^{9-11)}$ 특히 $\mathrm{n}$ 형과 $\mathrm{p}$ 형 열전 소재를 연결시키는 전극 소재의 선택과 열전 소재와 전극 간의 접합이 열전 소자 의 특성을 좌우하는 핵심 기술로 알려져 있다. 따라서 $\mathrm{CoSb}_{3}$ 를 중고온 영역에서 사용되어질 수 있는 열전소자 
로 활용하기 위해서 전극 소재의 개발 및 $\mathrm{CoSb}_{3}$ 와 전극 과의 접합은 열전모듈 제작을 위한 중요한 공정으로 부 각되고 있다. ${ }^{9-11)}$

최근 소결 및 소결 접합에서 매우 우수한 특성을 나타 내는 방전플라즈마 소결법을 적용한 $\mathrm{CoSb}_{3}$ 의 열전 소자 제조에 관한 연구들이 보고되고 있는데, 중고온형 전극 $(\mathrm{CuMo})$ 과 $\mathrm{CoSb}_{3}$ 사이에 $\mathrm{Ti}$ 를 $\mathrm{Cu}$ 의 확산 방지층으로 활 용하여 접합에 성공한 연구보고가 있었지만 $\mathrm{Ti}$ 과 $\mathrm{Sb}$ 에 의 해 생성되는 화합물인 $\mathrm{TiSb}$ 와 접합계면에서 생성되는 미 세 균열에 의하여 접합강도의 감소 및 열전성능이 저하 될 수 있다. $9,11,12)$ 이에 본 연구에서는 이러한 문제를 해 결하고자 $\mathrm{Al}$ 을 $\mathrm{Ti}$ 와 $\mathrm{CoSb}_{3}$ 사이에 삽입하여 $\mathrm{CoSb}_{3}$ 열전 소자를 제조하였으며 $\mathrm{CoSb}_{3}-\mathrm{Al}-\mathrm{Ti}$ 계면의 미세구조 변화 와 접합응력시험 및 전기 전도도 특성 측정을 통하여 접 합특성에 관하여 연구하고자 하였다.

\section{2. 실험 방법}

$\mathrm{Cu}-\mathrm{Mo}$ 전극은 $\mathrm{Cu}$ 분말(99.9\%, Sigma-Aldrich, USA), Mo 분말(99.9\%, Sigma-Aldrich, USA)를 3:7 5:5 부피 비 조성비로 하여 방전플라즈마 소결법으로 $980^{\circ} \mathrm{C}$ 에서 10 분간 진공분위기에서 $50 \mathrm{MPa}$ 의 압력으로 소결하여 두 께 $5 \mathrm{~mm}$ 의 $\mathrm{Cu}-\mathrm{Mo}$ 소결체를 제조하고 표면을 경면 연마 하여 준비하였다. $\mathrm{Cu}-\mathrm{Mo}$ 소결체와 $\mathrm{CoSb}_{3}$ 사이의 중간재 로 사용할 $\mathrm{Ti}$ 와 $\mathrm{Al}$ 은 각각 두께 $120 \mu \mathrm{m}$ 와 $100 \mu \mathrm{m}$ 의 박판 (99.99\%, Sigma-Aldrich, USA)을 준비하였다. 실험에 사용 된 $\mathrm{CoSb}_{3}$ 분말은 참고문헌13에 따라 유도 가열법으로 용 융 후 $600^{\circ} \mathrm{C}$ 에서 장시간 열처리하여 $\mathrm{CoSb}_{3}$ 단일상으로 제조되어 제공된 분말을 이용하였다.

열전 소자의 제조 공정은 먼저 준비된 $\mathrm{Cu}-\mathrm{Mo}$ 소결체 와 $\mathrm{Ti}$ 박판을 방전플라즈마 소결로에서 $900^{\circ} \mathrm{C}$ 온도에서 10 분간 진공 분위기에서 $50 \mathrm{MPa}$ 의 압력으로 접합 공정 을 실시하여 $\mathrm{Ti}$ 가 접합된 $\mathrm{Cu}-\mathrm{Mo}$ 전극을 준비하였으며, $\mathrm{CoSb}_{3}$ 분말을 방전플라즈마 소결로에서 $580^{\circ} \mathrm{C} 10$ 분간 진 공분위기 하에서 소결하여 소결체를 준비하였다. 다음으 로 준비된 전극과 $\mathrm{CoSb}_{3}$ 소결체의 접합을 위하여 준비된 $\mathrm{Al}$ 박판을 사이에 삽입하여 사용하여 방전플라즈마 소결 로를 이용하여 $500 \sim 580^{\circ} \mathrm{C}$ 온도에서 10 분간 진공분위기 하에서 접합을 실시하였다.

제조된 $\mathrm{Cu}-\mathrm{Mo}$ 전극과 $\mathrm{CoSb}_{3}$ 의 밀도는 Archimedes법을
이용하여 측정하였고, 열팽창계수를 측정하기 위하여 $5 \times$ $5 \times 25 \mathrm{~mm}$ 로 시편을 가공하여 dilatometer (ASTM E 22885 )를 사용하여 측정하였다. 접합계면은 FE-SEM (JSM$6700 \mathrm{~F}, \mathrm{Jeol}, \mathrm{Japan}$ )을 사용하여 미세구조 및 EDS (Energy Dispersive X-ray Spectrometer) 분석을 분석하였다. 접합면 의 강도는 시편을 $3 \times 3 \times 15 \mathrm{~mm}$ 로 가공하여 시편의 양단 을 에폭시 레진으로 고정한 후 인장강도 시험기(4204, Instron, USA)를 사용하여 상온에서 KSL 1599 규격에 의 거하여 인장 강도를 측정하였다. 접합 계면의 전기전도도 는 4단자 전기전도도 측정 장치(RZ2001I, Ozawa science, Japan)를 이용하여 4단자법으로 측정하였다.

\section{3. 결과 및 고찰}

Fig. 1은 방전 플라즈마 소결 중에 온도에 따른 가압축 의 변위를 측정하여 나타낸 결과로 이를 통하여 소결 중 에 발행하는 $\mathrm{CoSb}_{3}$ 분말의 치밀화 거동을 분석할 수 있 다. $\mathrm{CoSb}_{3}$ 분말은 약 $530^{\circ} \mathrm{C}$ 온도 부근에서 소결 수축이 급속히 정지되는 것을 확인 할 수 있으며 소결 온도인 $580^{\circ} \mathrm{C}$ 에 도달하였을 때 완전히 소결 수축이 중지되는 것 으로 보아 치밀화가 완료되었음을 알 수 있다. 이때 제조 된 시편의 소결밀도는 $7.62 \mathrm{~g} / \mathrm{cm}^{3}$ 로 $\mathrm{CoSb}_{3}$ 의 이론밀도 $\left(7.65 \mathrm{~g} / \mathrm{cm}^{3}\right)$ 에 근접한 값을 나타내었다.

Table 1 은 $580^{\circ} \mathrm{C}$ 에서 소결된 $\mathrm{CoSb}_{3}$ 소결체와 $980^{\circ} \mathrm{C}$ 에 서 소결된 $\mathrm{Cu}-\mathrm{Mo}$ 소결체 시편의 조성비에 따른 소결 밀

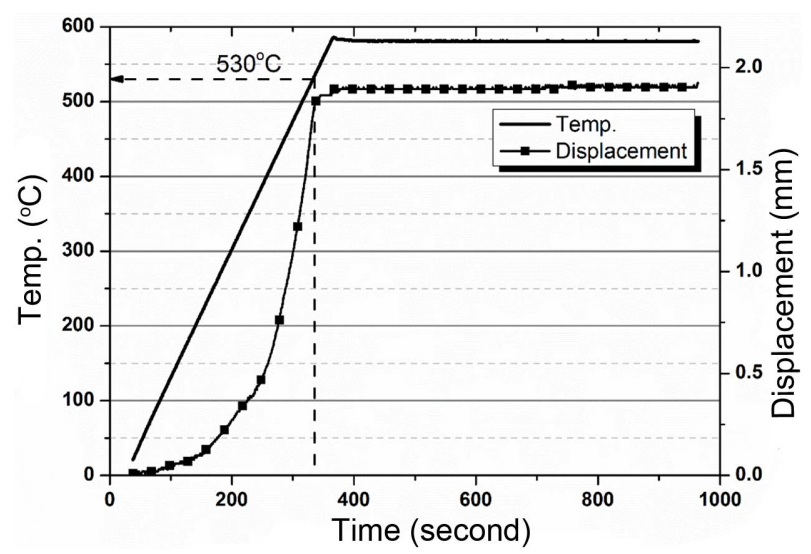

Fig. 1. Densification behavior of $\mathrm{CoSb}_{3}$ powder during spark plasma sintering process.

Table 1. Relative Density and Thermal Expansion Coefficient of Sintered $\mathrm{CoSb}_{3}$ and $\mathrm{Cu}-\mathrm{Mo}$ Electrodes

\begin{tabular}{cccc}
\hline Material & Composition $(\mathrm{Cu}: \mathrm{Mo}, \mathrm{Vol}$ ratio $)$ & Relative density (\%) & Thermal expansion coefficient $\left(10^{-6} \mathrm{~K}^{-1}\right)$ \\
\hline \multirow{2}{*}{$\mathrm{Cu}-\mathrm{Mo}$} & $3: 7$ & 99 & 8.43 \\
& $4: 6$ & 99 & 9.82 \\
$\mathrm{CoSb}_{3}$ & $5: 5$ & 99 & 11.37 \\
\hline
\end{tabular}




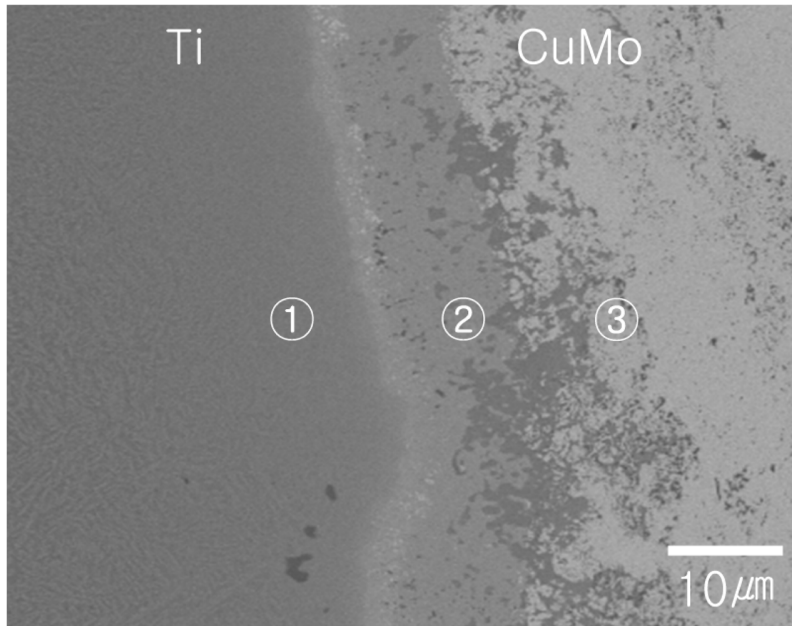

Fig. 2. Microstructure of $\mathrm{Ti} / \mathrm{Cu}-\mathrm{Mo}$ interface joined at $900^{\circ} \mathrm{C}$.

도와 열팽창계수 측정 결과를 나타낸 것으로 $\mathrm{Cu}: \mathrm{Mo}=$ $5: 5 \mathrm{vol} \%$ 조성의 경우가 $11.21 \times 10^{-6} \mathrm{~K}^{-1}$ 결과를 나타내 었는데 이는 소결된 $\mathrm{CoSb}_{3}$ 의 열팽창계수와 근사한 값으 로 $\mathrm{Cu}: \mathrm{Mo}=5: 5 \mathrm{vol} \%$ 조성의 전극이 재료간의 열팽창차 이에 의한 결함을 최소화 할 수 있을 것으로 예상된다.

Fig. 2는 $\mathrm{Cu}: \mathrm{Mo}=5: 5$ 부피비 조성의 $\mathrm{Cu}-\mathrm{Mo}$ 소결체를 이용하여 진공 분위기에서 $900^{\circ} \mathrm{C}$ 에서 10 분 동안 유지 조 건으로 $\mathrm{Ti}$ 와의 접합을 실시하여 제조된 $\mathrm{Ti} / \mathrm{Cu}-\mathrm{Mo}$ 전극의 $\mathrm{Ti}$ 와 $\mathrm{Cu}-\mathrm{Mo}$ 간의 접합계면의 미세구조와 $\mathrm{EDS}$ 분석 결과 이다. $\mathrm{Ti}$ 와 $\mathrm{Cu}-\mathrm{Mo}$ 의 계면에서는 어떠한 결함의 발생도 관 찰되지 않은 매우 양호한 결합 상태를 나타내고 있으며
Table 2. EDS Analysis Results of the Marked Areas in Fig. 2.

\begin{tabular}{ccccc}
\hline Element(At\%) & Position & (1) & (2) & (3) \\
\cline { 1 - 4 } $\mathrm{Ti}$ & 100 & 54 & 0 \\
$\mathrm{Cu}$ & 0 & 32 & 46 \\
$\mathrm{Mo}$ & 0 & 14 & 64 \\
$\mathrm{Total}$ & 100 & 100 & 100 \\
\hline
\end{tabular}

$\mathrm{EDS}$ 분석 결과를 살펴보면 $\mathrm{Ti}$ 와 $\mathrm{Cu}-\mathrm{Mo}$ 사이의 계면에서 는 $\mathrm{Ti}$ 와 $\mathrm{Cu}$ 및 $\mathrm{Mo}$ 간의 반응에 의해 계면이 형성되지만 공정 온도인 $900^{\circ} \mathrm{C}$ 에서 반응층의 두께는 약 $10 \mu \mathrm{m}$ 로 제 한적이며 계면에서 가까운 $\mathrm{Ti}$ 쪽(Fig. 2(1))에서도 $\mathrm{Cu}$ 가 검 출되지 않음을 보여주고 있다. 따라서 $\mathrm{CoSb}_{3}$ 와 $\mathrm{Cu}-\mathrm{Mo}$ 의 접합에 있어서 공정 온도인 $500 \sim 580^{\circ} \mathrm{C}$ 의 영역에서는 $\mathrm{Ti}$ 이 $\mathrm{Cu}$ 가 $\mathrm{CoSb}_{3}$ 내부로 확산되는 것을 충분히 방지할 수 있으리라 사료된다.

Fig. 3 는 방전플라즈마 소결법으로 $580^{\circ} \mathrm{C}$ 에서 10 분간 소결된 $\mathrm{CoSb}_{3}$ 와 $\mathrm{CuMo} / \mathrm{Ti}$ 전극의 접합을 위해 $\mathrm{Al}$ 을 중간 재로 삽입하여 방전플라즈마 소결로에서 $500 \sim 580^{\circ} \mathrm{C}$ 의 온도에서 10 분간 접합하여 제조된 $\mathrm{CoSb}_{3} / \mathrm{Al} / \mathrm{Ti} / \mathrm{CuMo}$ 시 편의 $\mathrm{Al} / \mathrm{Ti}$ 계면의 미세구조를 보여주고 있다. $\mathrm{Al}$ 과 $\mathrm{Ti}$ 의 계면에서는 $500^{\circ} \mathrm{C}$ 의 온도에서부터 반응층이 형성되기 시 작하며 $580^{\circ} \mathrm{C}$ 에 이르러서는 $4 \sim 5 \mu \mathrm{m}$ 정도의 두께를 나타 냄을 확인할 수 있다. 하지만 $\mathrm{Al} / \mathrm{Ti}$ 계면에서는 미세 균 열 등의 결함이 발견되지 않는 우수한 접합 상태를 보여 주고 있다.

Fig. 4는 $\mathrm{CoSb}_{3} / \mathrm{Al} / \mathrm{Ti} / \mathrm{CuMo}$ 시편의 $\mathrm{CoSb}_{3} / \mathrm{Al}$ 계면의 미

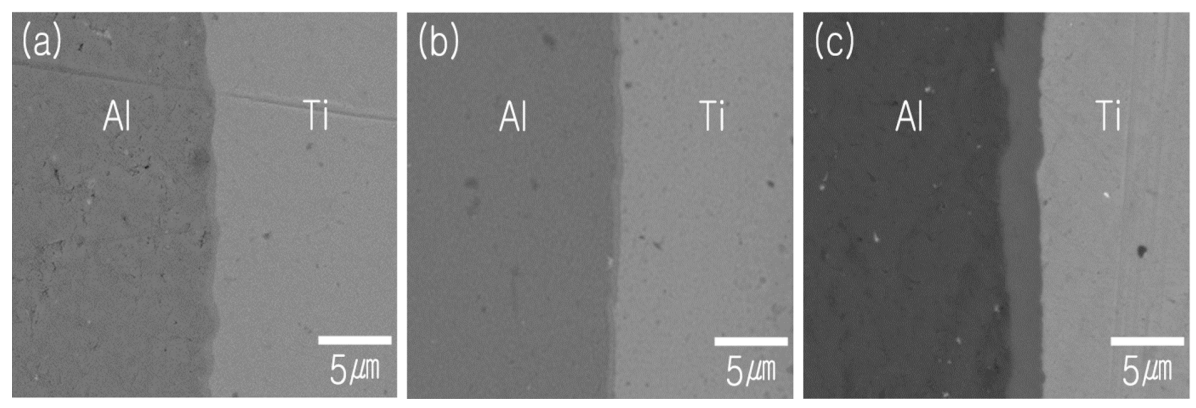

Fig. 3. Back-scattered electron images of $\mathrm{Al} / \mathrm{Ti}$ interfaces joined at various temperatures : (a) $500^{\circ} \mathrm{C},(\mathrm{b}) 550^{\circ} \mathrm{C}$, and (c) $580^{\circ} \mathrm{C}$.
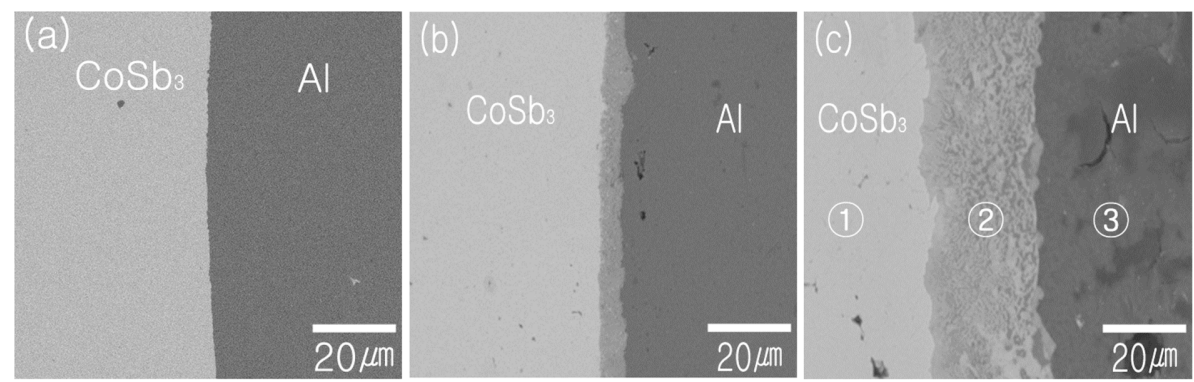

Fig. 4. Back-scattered electron images of $\mathrm{CoSb}_{3} / \mathrm{Al}$ interfaces joined at various temperatures : (a) $500^{\circ} \mathrm{C},(\mathrm{b}) 550^{\circ} \mathrm{C}$, and (c) $580^{\circ} \mathrm{C}$. 
Table 3. EDS Analysis Results of the Marked Areas in Fig. 4(c)

\begin{tabular}{|c|c|c|c|}
\hline Element(At\%) Position & (1) & (2) & (3) \\
\hline $\mathrm{Al}$ & 0 & 57.2 & 100 \\
\hline Co & 24.6 & 9.2 & 0 \\
\hline $\mathrm{Sb}$ & 75.4 & 33.6 & 0 \\
\hline Total & 100 & 100 & 100 \\
\hline
\end{tabular}

세구조를 보여주고 있으며 Table 3은 $\mathrm{EDS}$ 를 이용한 계면 에서 성분 분석 결과를 나타내고 있다. $500^{\circ} \mathrm{C}$ 에서 접합된 시편의 경우 $\mathrm{CoSb}_{3}$ 와 $\mathrm{Al}$ 계면에서 반응층의 형성이 관찰 되지 않고 있지만 $550^{\circ} \mathrm{C}$ 에서 접합된 시편에서는 $\mathrm{Al}-\mathrm{Co}-$ $\mathrm{Sb}$ 로 이뤄진 반응층 형성이 관찰되기 시작하며 접합 온 도가 상승함에 따라 반응층의 두께가 급격히 증가하고 있 음을 알 수 있다. 하지만 $\mathrm{Ti}$ 만 단독으로 사용된 경우와는 달리 반응층의 형성과 두께의 증가에도 불구하고 계면에

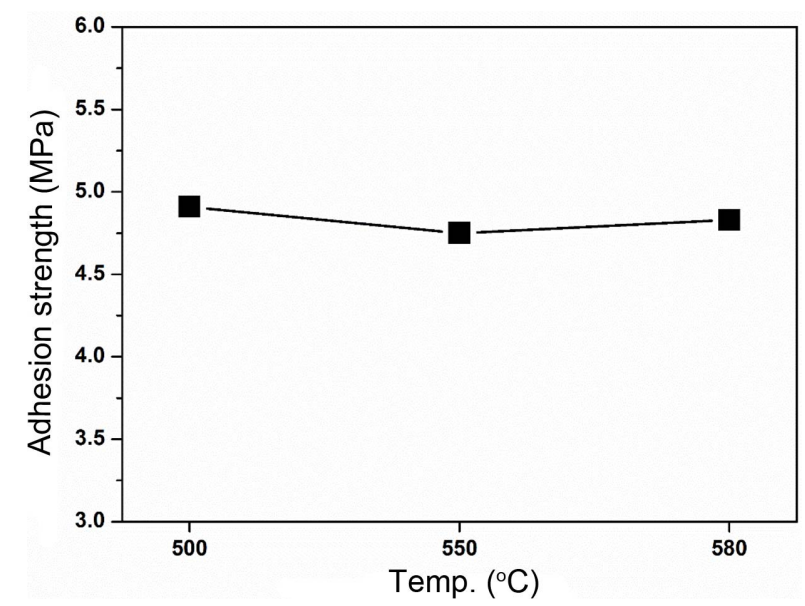

Fig. 5. Adhesion strength of $\mathrm{CoSb}_{3} / \mathrm{Al} / \mathrm{Ti} / \mathrm{CuMo}$ joint with joining temperatures.

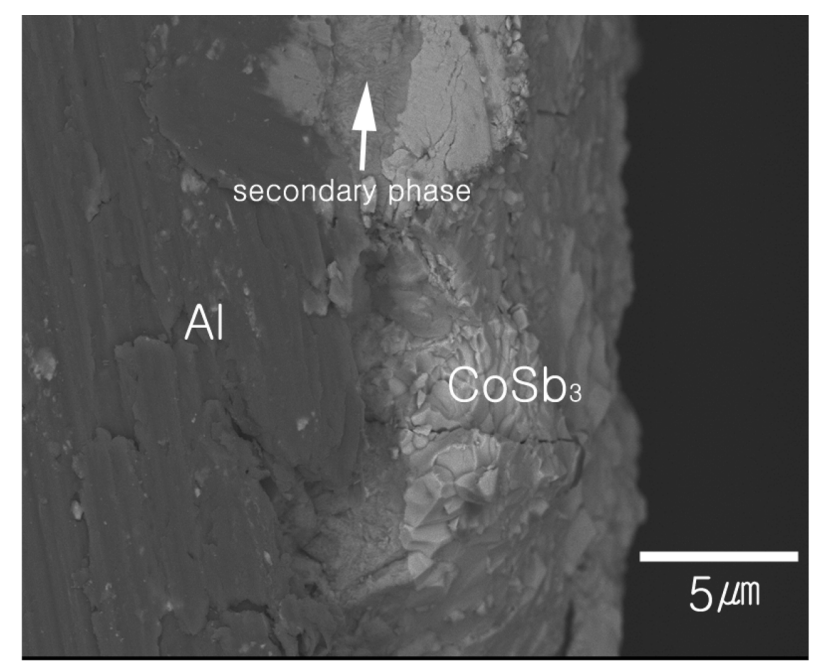

Fig. 6. Back-scattered electron image of interfacial failure at $\mathrm{CoSb}_{3} / \mathrm{Al} / \mathrm{Ti} / \mathrm{CuMo}$ joint.
서 미세 균열이 발견되지 않고 매우 양호한 접합 상태를 나타내고 있다. ${ }^{12)}$

Fig. 5은 접합온도에 따른 $\mathrm{CoSb}_{3} / \mathrm{Al} / \mathrm{Ti} / \mathrm{CuMo}$ 접합 시편 의 부착강도를 측정한 결과로 접합온도에 따른 부착 강 도는 약 $4.7 \sim 4.9 \mathrm{MPa}$ 로 대동소이한 값을 나타내었다. 따 라서 접합온도에 따라 발생된 $\mathrm{CoSb}_{3} / \mathrm{Al} / \mathrm{Ti} / \mathrm{CuMo}$ 시편에 서의 반응층들이 접합력에 큰 영향을 미치지 않는 것으 로 판단된다. 하지만 이러한 부착 강도 결과는 이전 연구 에서 보고되었던 $\mathrm{Ti}$ 단독으로 삽입하여 접합한 결과 ${ }^{12)}$ 와 비교하여 2 배 이상의 접합강도 향상을 가져온 우수한 결 과이다.

Fig. 6 은 $580^{\circ} \mathrm{C}$ 에서 접합하여 제조된 $\mathrm{CoSb}_{3} / \mathrm{Al} / \mathrm{Ti} / \mathrm{CuMo}$ 시편의 접합강도 시험 후 계면에서의 파괴 양상을 나타 내고 있다. 시편의 파괴는 $\mathrm{CoSb}_{3} / \mathrm{Al}$ 계면에서만 파괴가 진행되었으며 $\mathrm{CoSb}_{3}$ 와 $\mathrm{Al}$ 사이에 생성된 반응층에서 주 로 파괴가 진행되었음을 확인할 수 있다.

Fig. 7는 Fig. 8에서 나타내는 것처럼 $\mathrm{CoSb}_{3}$ 사이에 $\mathrm{Al} /$ $\mathrm{Ti} / \mathrm{Al}$ 을 삽입하여 $580^{\circ} \mathrm{C}$ 에서 접합한 후 시편을 준비하여 시편 좌측에서부터 (1) (4)까지 측정 위치를 변화시키면 서 4단자법을 이용하여 거리에 따른 저항을 나타낸 것으 로, 시편의 전기저항은 거리가 증가함에 선형적으로 비례 하여 증가하고 있다. 이러한 결과는 $\mathrm{Cu}$ 의 확산 방지를 위

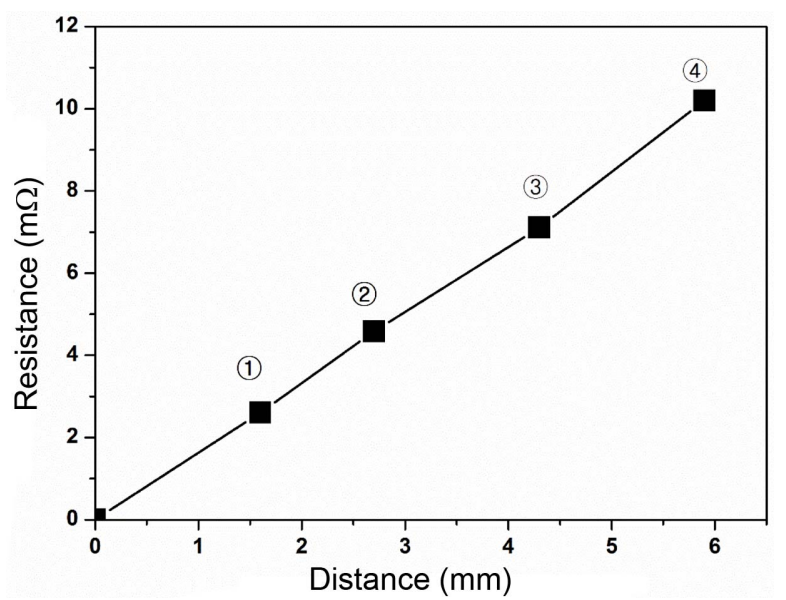

Fig. 7 The variation of resistance of $\mathrm{CoSb}_{3} / \mathrm{Al} / \mathrm{Ti} / \mathrm{Al} / \mathrm{CoSb}_{3}$ specimen with distance.

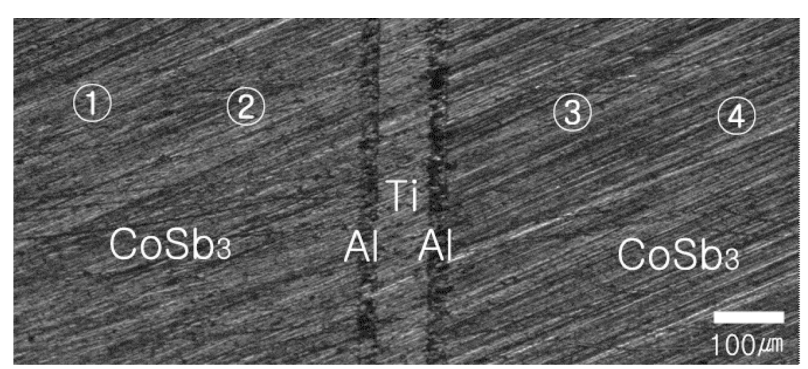

Fig. 8. The optical microscope image of the specimen for measuring electrical resistance. 
해 삽입된 $\mathrm{Ti}$ 와 접합력 향상을 위해 삽입된 $\mathrm{Al}$ 에 의해 형 성되는 여러 반응층들이 $\mathrm{CoSb}_{3}$ 의 열전 소자 제조 시에 계면에서 전기저항을 증가시키지 않기 때문에 열전 소자 의 성능을 저하시키지 않을 것으로 사료된다.

\section{4. 결}

중고온 영역에서 활용될 수 있는 $\mathrm{CoSb}_{3}$ 열전 소재의 열 전 소자를 제조하기 위해 $\mathrm{CoSb}_{3}$ 와 $\mathrm{Cu}-\mathrm{Mo}$ 계 전극 소재와 의 접합을 $\mathrm{Ti}$ 과 $\mathrm{Al}$ 을 중간재로 사용하여 방전플라즈마 소 결로를 활용하여 수행하였다. 확산 방지막으로 삽입된 $\mathrm{Ti}$ 는 $\mathrm{Cu}$ 의 확산의 방지를 확인할 수 있었으며, $\mathrm{Ti}$ 와 $\mathrm{CoSb}_{3}$ 의 접합력 증대를 위해 삽입된 $\mathrm{Al}$ 은 접합 온도가 상승함 에 따라 $\mathrm{Al}-\mathrm{Co}-\mathrm{Sb}$ 계의 반응층을 형성하지만 이에 따른 접 합력의 영향은 미미한 것으로 관찰되었으며, $\mathrm{CoSb}_{3} / \mathrm{Al} / \mathrm{Ti}$ 계면에서의 파괴 거동을 관찰한 결과 파괴는 주로 $\mathrm{CoSb}_{3}$ 와 $\mathrm{Al}$ 에 의해 형성된 반응층에서 진행됨을 알 수 있었다. $\mathrm{Al}$ 의 중간재 사용은 $\mathrm{Ti}$ 단독으로 사용하였을 경우보다 2 배 이상의 부착강도 향상을 가져왔으며 또한 삽입된 $\mathrm{Al}$ 및 $\mathrm{Ti}$ 에 의해 접합 공정 중에 형성되는 반응층들은 $\mathrm{CoSb}_{3}$ 열전 소자의 전기저항을 증가시키지 않기 때문에 $\mathrm{CoSb}_{3}$ 계 열전 소자의 제조에 매우 유용할 것으로 사료된다.

\section{REFERENCES}

1. D. M. Rowe, "Thermoelectrics, an Environmentally Friendly Source of Electrical Power," Renew. Energ., 16 [1-4] 1251-56 (1999).

2. F. J. Disa, "Thermoelectric Cooling and Power Generation," Science, 285 [5428] 703-06 (1999).

3. Y. Shinohara, Y. Imai, and Y. Isoda, "Thermoelectric Properties of Segmented Pb-Te Systems with Graded Carrier
Concentrations," pp. 386-89, Proc. ICT '97, 1997.

4. S. Gorsse, P. Bellanger, and Y. Brechet, "Nanostructuration via Solid State Transformation as a Strategy for Improving the Thermoelectric Efficiency of PbTe Alloys," Acta Mater., 59 [19] 7425-437 (2011).

5. B. C. Sales, D. Mandrus, and R. K. Williams, "Filled Skutterudite Antimonides : A New Class of Thermoelectric Materials," Science, 272 [5266] 1325-28 (1996).

6. G. S. Nolas, J. L. Cohn, and G. A. Slack, "Effect of Partial Void Filling on the Lattice Thermal Conductivity of Skutterudites," Phys. Rev. B, 58 [1] 164-70 (1998).

7. X. F. Tang, L. M. Zhang, R. Z. Yuan, L. D. Chen, T. Goto, T. Hirai, W. Chen, and C. Uher, "High Temperature Thermoelectric Properties of n-type $\mathrm{Ba}_{\mathrm{y}} \mathrm{Ni}_{\mathrm{x}} \mathrm{Co}_{4-\mathrm{x}} \mathrm{Sb}_{12}$," J. Mater. Res., 16 [12] 3343-46 (2001).

8. M. Puyet, B. Lenoir, A. Dauscher, M. Dehmas, C. Stiewe, and E. Muller, "High Temperature Transport Properties of Partially Filled $\mathrm{Ca}_{\mathrm{x}} \mathrm{Co}_{4} \mathrm{Sb}_{12}$ Skutterudites," J. Appl. Phys., 95 [9] 4852-55 (2004).

9. J. Fan, L. Chen, S. Bao, and X. Shi, "Joining of Mo to $\mathrm{CoSb}_{3}$ by Spark Plasma Sintering by Inserting a Ti Interlayer," Mater. Lett., 58 [30] 3876-878 (2004).

10. S. J. Lee and S. K. Wu, "Infrared Joining Strength and Interfacial Microstructures of Ti-48Al-2Nb-2Cr Intermetallics Using Ti-15Cu-15Ni Foil," Intermetallics, 7 [1] 11-21 (1999).

11. Z. Degang, L. Xiaoya, H. Lin, J. Wan, and L. Chen, "High Temperature Reliability Evaluation of $\mathrm{CoSb}_{3} /$ Electrode Thermoelectric Joints," Intermetallics, 17 [3] 136-41 (2009).

12. K. H. Kim, J. S. Park, and J. P. Ahn, "Joining and Properties of Electrode for $\mathrm{CoSb}_{3}$ Thermoelectric Materials Prepared by a Spark Plasma Sintering Method," J. Kor. Cryst. Grow. Cryst. Tech., 20 [1] 30-34 (2010).

13. M. J. Kim, H. M. Choi, S. C. Ur, and I. H. Kim, "Thermoelectric Properties of $\mathrm{Co}_{1-\mathrm{x}} \mathrm{Ni}_{\mathrm{x}} \mathrm{Sb}_{3}$ Prepared by Encapsulated Induction Melting," Kor. J. Mater. Res., 16 [6] 37781 (2006). 